\title{
Famciclovir for ophthalmic zoster: a randomised aciclovir controlled study
}

Stephen Tyring, Reinhard Engst, Christine Corriveau, Nicole Robillard, Sylvie Trottier, Steven Van Slycken, Rachel A Crann, Leslie A Locke, Robin Saltzman, Alan G Palestine, for the Collaborative Famciclovir Ophthalmic Zoster Research Group`

University of Texas Medical Branch, Galveston, TX, USA S Tyring

Dermatological Hospital of the Technical University, Munich, Germany

R Engst

Notre Dame Hospital, Montreal, Quebec, Canada

C Corriveau

N Robillard

Centre Hôpital de l'Université Laval, Ste-Foy, Quebec, Canada

S Trottier

Gent, Belgium S Van Slycken

SmithKline Beecham, Collegeville, PA, USA R A Crann

L A Locke

R Saltzman

Georgetown

University,

Washington, DC, USA

A G Palestine

${ }^{\star}$ Members are listed at the end of the paper.

Correspondence to:

Alan G Palestine, MD, 1145

19th Street, NW, Suite 900,

Washington, DC, 20036,

USA

apalest@erols.com

Accepted for publication 20 December 2000

\begin{abstract}
Aims-To compare the efficacy and safety of famciclovir with aciclovir for the treatment of ophthalmic zoster.

Methods-Randomised, double masked, aciclovir controlled, parallel group in 87 centres worldwide including 454 patients with ophthalmic zoster of trigeminal nerve $\left(V_{1}\right)$ comprised the intent to treat population. Oral famciclovir $500 \mathrm{mg}$ three times daily or oral aciclovir $800 \mathrm{mg}$ five times daily for 7 days. Assessments included day 0 (screening), days 3 and 7 (during treatment), days 10, 14, 21, 28 and monthly thereafter, up to 6 months (follow up). Proportion of patients who experienced ocular manifestations, severe manifestations and non-severe manifestations; loss of visual acuity was the main outcome measure.
\end{abstract}

Results-The percentage of patients who experienced one or more ocular manifestations was similar for famciclovir (142/ $245,58.0 \%)$ and aciclovir $(114 / 196,58.2 \%)$ recipients, with no significant difference between groups (OR 0.99; 95\% CI 0.68, 1.45). The percentage of patients who experienced severe and non-severe manifestations was similar between groups, with no significant difference. The prevalence of individual ocular manifestations was comparable between groups. There was no significant difference between groups for visual acuity loss.

Conclusion-Famciclovir $500 \mathrm{mg}$ three times daily was well tolerated and demonstrated efficacy similar to aciclovir $800 \mathrm{mg}$ five times daily.

(Br f Ophthalmol 2001;85:576-581)

In $50 \%-72 \%$ of patients with ophthalmic herpes zoster (HZO), involvement of the ocular structures leads to ocular manifestations ranging from self limited processes to chronic ocular inflammation or neuropathy which may lead to visual loss. ${ }^{1-3}$ The mechanism of ocular manifestations is thought to include active viral replication within the eye and ophthalmic trigeminal nerve, followed by vascular and neural inflammation and damage.

Aciclovir treatment for $\mathrm{HZO}$ has been shown to be beneficial to patients and is currently the standard of care among health practitioners. ${ }^{4-6}$ Oral aciclovir at doses of $600-800 \mathrm{mg}$ five times daily for 10 days significantly reduced the acute signs and symptoms of the disease and the incidence of common ocular manifestations such as dendriform keratopathy, uveitis, and stromal keratitis. ${ }^{7}$ However, aciclovir has poor and variable bioavailability requiring high frequency dosing regimens which can lead to difficulties with compliance. ${ }^{9} 10$

Famciclovir is the oral form of penciclovir, a nucleoside analogue which shares the same antiviral spectrum as aciclovir for herpes viruses and has similar potency and selectivity. The oral bioavailability of penciclovir is $77 \%$ following administration of famciclovir, ${ }^{11}$ significantly higher than the bioavailability of aciclovir $(10 \%-20 \%) .^{12}$ In addition, the intracellular half life of penciclovir triphosphate is significantly longer than that of aciclovir triphosphate in cells infected with varicella zoster virus in vitro (1-11 hours for penciclovir triphosphate compared with $\leqslant 1$ hour for aciclovir triphosphate). ${ }^{13}$

Famciclovir is currently approved in over 60 countries for treatment of acute uncomplicated herpes zoster. Previous studies have been undertaken to compare the efficacy and safety of famciclovir and aciclovir in the treatment of uncomplicated herpes zoster. In one study, famciclovir dosed at $250 \mathrm{mg}$ three times daily for 7 days was as effective as $800 \mathrm{mg}$ aciclovir dosed five times daily for 7 days in the treatment of the acute signs and symptoms of herpes zoster. ${ }^{14}$ When treatment was initiated within 72 hours of the onset of zoster rash, three doses of famciclovir $(250 \mathrm{mg}, 500 \mathrm{mg}$, and $750 \mathrm{mg}$ three times daily) were all as effective as aciclovir ( $800 \mathrm{mg}$ five times daily) in cutaneous lesion resolution. This includes the median times to loss of vesicles, full crusting, and loss of crusts. ${ }^{15} 16$ The time to cessation of new lesion formation and time to loss of acute pain was also comparable in patients receiving famciclovir and aciclovir. In patients who received treatment within 48 hours of rash onset, famciclovir significantly decreased the duration of zoster associated pain compared with aciclovir. ${ }^{15} 16$ In addition to accelerating the resolution of the acute zoster signs and symptoms, famciclovir has been proved to reduce the duration of postherpetic neuralgia. ${ }^{17}$

Famciclovir's unique pharmacokinetic properties and demonstrated efficacy in acute uncomplicated herpes zoster prompted the investigation of famciclovir for the treatment of patients with $\mathrm{HZO}$.

\section{Materials and methods}

PROTOCOL

Healthy male or female patients, aged 18 years or older, with clinically diagnosed localised zoster in which the dermatome primarily 
Table 1 Protocol defined ocular manifestations of herpes zoster

Severe ocular manifestations

Choroiditis

Deep keratitis

Exophthalmos

Optic neuritis

Keratic precipitates

Scleritis

Necrotising scleritis

Synechia

Glaucoma

Non-severe ocular manifestations

Conjunctivitis

Episcleritis

Epitheliopathy

Subepithelial infiltrates

Non-vision interfering corneal scarring

*Although anterior uveitis and iridocyclitis are often used interchangeably, for this study a distinction was made in that anterior uveitis involved inflammation in the anterior chamber, whereas iridocyclitis involved inflammation of the anterior chamber combined with inflammation in the vitreous.

Paralytic ptosis

Retinitis

Iridocyclitis or anterior uveitis ${ }^{\star}$

Cicatricial lid retraction

Vision impairing corneal scarring or vascularisation

Partial or complete nerve palsy III, IV, V, VI involved was the ophthalmic branch of the trigeminal nerve $\left(\mathrm{V}_{1}\right)$, were eligible for inclusion. Written informed consent was obtained from each patient before entry into the study.

Patients were excluded if their zoster rash was present for more than 72 hours at the time of receiving the first dose of study medication, if other significant, pre-existing, non-zoster associated pathology was present, if they were pregnant or breastfeeding, or had received antiviral therapy during the previous 14 days. Patients were also excluded if they were immunocompromised, were receiving immunomodifying therapy of any kind, or were known or suspected to be HIV seropositive at the time of enrolment. An HIV serology was performed if considered appropriate by the patient, physician, and ERC/IRB.

Patients were randomly assigned, in a double masked fashion, to one of two treatment regimens for 7 days at screening (day 0 ): famciclovir $500 \mathrm{mg}$ three times daily or aciclovir $800 \mathrm{mg}$ five times daily. Study visits occurred during treatment on days 3 and 7 , during follow up on days 10,14,21, and 28, and monthly for months 2-6. An ophthalmic examination which included assessment of specific protocol defined ocular manifestations, best corrected visual acuity, and intraocular pressure (IOP) for each eye was performed at each visit.

\section{EFFICACY ASSESSMENTS}

The primary efficacy parameter was the proportion of patients who experienced an ocular manifestation during the 6 month study period. Ocular manifestations were protocol defined (Table 1). Key secondary efficacy parameters included the proportion of patients who experienced severe ocular manifestations and non-severe ocular manifestations. The prevalence of individual ocular manifestations and the proportion of patients who experienced a loss of visual acuity during the study, defined as visual acuity at study end (month 6) demonstrating a deterioration of three or more lines from the best visual acuity obtained at any previous visit during the study, were also analysed. Although anterior uveitis and iridocyclitis are often used interchangeably, for this study a distinction was made in that anterior uveitis involved inflammation in the anterior chamber, whereas iridocyclitis involved inflammation of the anterior chamber combined with inflammation in the vitreous.

\section{STATISTICAL ANALYSIS}

For the proportion end points, any patient who reported a particular symptom at baseline was considered unable to develop the condition during the study and was therefore excluded from the analysis. Any patient who had the symptom unassessed at baseline (that is, missing data) was excluded from the assessment of experiencing that particular symptom during the study as the presence or absence of any symptom could not be assumed. Analyses were performed on all observed data. The formal statistical analysis used logistic regression, based on odds ratios. The odds ratio for a proportion end point was constructed as the odds of famciclovir recipients developing an ocular manifestation(s) relative to the odds of aciclovir recipients developing a manifestation(s). Odds ratios are provided with the corresponding $95 \%$ confidence intervals.

\section{SAFETY}

Safety was assessed by recording reported adverse events and monitoring of haematological and clinical parameters. Only serious adverse experiences were to be collected 30 days or more after the last dose of study medication through the month 6 follow up visit.

Blood was taken for measurement of haematological and clinical chemistry parameters before the first dose on the day of enrolment and following completion of treatment on day 7. Clinical laboratory results were evaluated by calculating mean differences from baseline and by identifying laboratory values of potential clinical concern (values that had changed from baseline by more than a specified amount and were outside the sponsor defined extended normal range).

This is the largest controlled study of patients with HZO to date. Sample sizes were based on feasibility considerations. Notwithstanding this, the following figures gave an indication of differences that could be detected. A total of 130 evaluable patients per treatment group were sufficient to detect a $20 \%$ difference between the groups in the proportion of patients who developed ocular manifestations at some stage during the study. This assumed at least $90 \%$ power and testing at the $5 \%$ level.

It was considered that 200 patients per group were needed in order to obtain the required number of evaluable patients. However, target enrolment was revised to 479 patients (200 per treatment arm +79 additional) owing to the finding that the initial aciclovir recipients received study medication which was not bioequivalent to the commercial aciclovir formulation. Inclusion of the patients who received the non-bioequivalent aciclovir could have biased the results against the aciclovir treatment group. Thus, these nonbioequivalent aciclovir recipients were not included in the intent to treat population. 


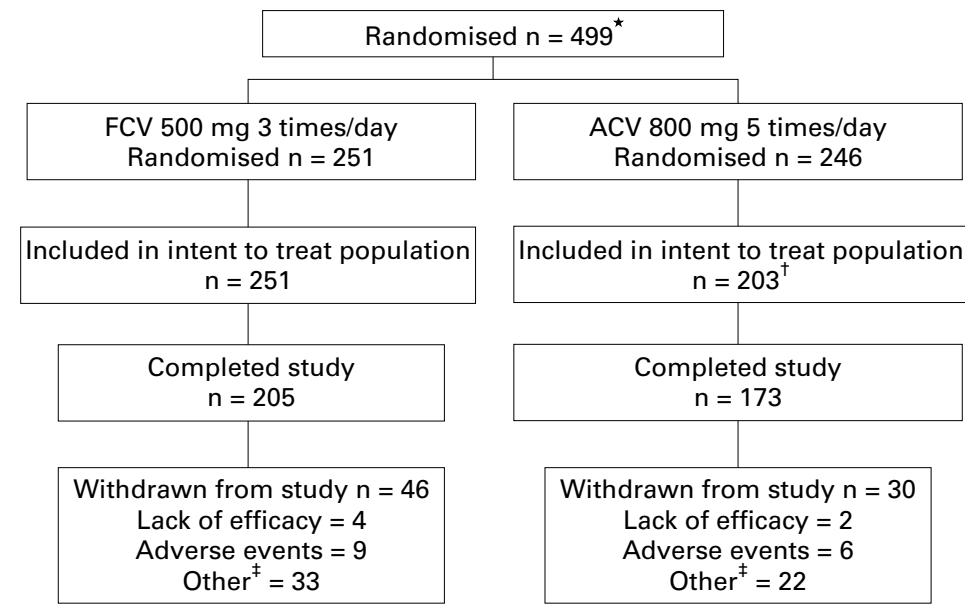

Figure 1 Trial profile. *Includes two patients who were randomised but never received medication. +43 patients received non-bioequivalent aciclovir and thus were excluded from the intent to treat population. $\neq$ "Other" reasons included lack of patient compliance, patient lost to follow up, and protocol violation.

Table 2 Demographic and zoster characteristics

\begin{tabular}{lll}
\hline \multicolumn{3}{c}{ Treatment group } \\
\cline { 2 - 3 } Demographic/zoster characteristic & $\begin{array}{l}\text { Famciclovir 500 mg three } \\
\text { times daily }(n=251)\end{array}$ & $\begin{array}{l}\text { Aciclovir } 800 \text { mg } 5 \times \text { daily } \\
(n=203)\end{array}$ \\
\hline Male, No (\%) & $120(48 \%)$ & $93(46 \%)$ \\
Mean age, years (range) & $59(19-93)$ & $58(20-93)$ \\
Race, No (\%) & $235(94 \%)$ & $195(96 \%)$ \\
$\quad$ White & $10(4 \%)$ & $6(3 \%)$ \\
Black & $6(2 \%)$ & $2(1 \%)$ \\
Other & $135(54 \%)$ & $117(58 \%)$ \\
Duration of zoster rash at start of treatment & $86(42 \%)$ \\
$0-48$ Hours & $116(46 \%)$ & $140(69 \%)$ \\
$49-72$ Hours & $172(69 \%)$ & $46(23 \%)$ \\
Number of lesions within primary affected dermatome & $17(8 \%)$ \\
$1-24$ & $62(25 \%)$ & \\
$25-50$ & $17(7 \%)$ & \\
$>50$ & & \\
\hline
\end{tabular}

Table 3 Percentage of patients with common ocular manifestations of herpes zoster at baseline

\begin{tabular}{|c|c|c|}
\hline & \multicolumn{2}{|l|}{ Treatment group } \\
\hline & $\begin{array}{l}\text { Famciclovir } 500 \mathrm{mg} \\
\text { three times daily } \\
(n=251)\end{array}$ & $\begin{array}{l}\text { Aciclovir } 800 \mathrm{mg} 5 \times \text { daily } \\
(n=203)\end{array}$ \\
\hline \multicolumn{3}{|l|}{ Severe manifestations } \\
\hline Glaucoma* & $9 \%$ & $8 \%$ \\
\hline Anterior uveitis & $6 \%$ & $6 \%$ \\
\hline Iridocyclitis & $4 \%$ & $5 \%$ \\
\hline \multicolumn{3}{|l|}{ Non-severe manifestations } \\
\hline Inflammation of conjunctiva & $55 \%$ & $52 \%$ \\
\hline Punctate epithelial keratopathy & $13 \%$ & $12 \%$ \\
\hline Episcleritis & $10 \%$ & $9 \%$ \\
\hline
\end{tabular}

${ }^{\star}$ Glaucoma was defined as intraocular pressure $>20 \mathrm{~mm} \mathrm{Hg}$

Four hundred and ninety seven patients (251 famciclovir, 246 aciclovir) received at least one dose of double masked study medication. Analyses were performed on the intent to treat population (251 famciclovir, 203 aciclovir), comprising all patients who received at least one dose of study medication excluding the 43 non-bioequivalent aciclovir recipients.

MASKING

Eligible patients were sequentially allocated a unique patient identification number according to a computer generated randomisation code which determined their treatment group. The patient number determined assignment to the famciclovir or aciclovir treatment group in a $1: 1$ ratio.
Each patient received one treatment box clearly marked with his/her patient number. Each box contained sufficient medication for 7 days' treatment presented in daily cards. The study medication was blister packaged and each card displayed the times (07:00, 11:00, 15:00, 19:00, 23:00) and corresponding study medication to be taken.

\section{PATIENT RANDOMISATION AND BLINDING}

Famciclovir was provided as $500 \mathrm{mg}$ white coated tablets and aciclovir was provided as $400 \mathrm{mg}$ capsules. Tablets and capsules containing placebo were identical in appearance and taste to those containing the active study medication. Patients randomised to famciclovir treatment took famciclovir $500 \mathrm{mg}$ tablets three times daily $(07: 00,15: 00,23: 00)$ and two placebo aciclovir capsules five times daily at 7:00, 11:00, 15:00, 19:00, and 23:00. Patients randomised to aciclovir treatment took aciclovir $800 \mathrm{mg}(2 \times 400 \mathrm{mg}$ capsules $)$ five times daily along with one placebo famciclovir tablet at 07:00, 15:00, and 23:00.

The patient, the investigator, and the sponsor personnel directly involved in monitoring the study or reviewing the data had no knowledge of what treatment had been allocated until the code was broken and the data analysed. The medication code for a particular patient was only to be broken in the event of a serious adverse experience which the investigator felt could not be adequately treated without knowing the identity of the study medication.

\section{Results}

Of the 499 patients randomised to the study, 497 patients received at least one dose of study medication (Fig 1). The intent to treat population comprised 454 patients. The demographic characteristics were comparable between treatment groups (Table 2). Slightly more than half of the population was female; mean age was 58 years (range 19-93 years). Zoster characteristics at baseline were also comparable between treatment groups (Table 2). More than half of the patients were enrolled within 48 hours of rash onset and approximately one third of patients had $\geqslant 25$ lesions.

The presence of severe and non-severe ocular manifestations at baseline was also comparable between treatment groups (Table 3). The most frequent severe ocular manifestations at baseline included glaucoma (39/454, 9\%), anterior uveitis $(24 / 454,6 \%)$, and iridocyclitis $(21 / 454,5 \%)$. The most frequent non-severe ocular manifestations at baseline included inflammation of the conjunctiva (242/454, $53 \%)$, punctate epithelial keratopathy (56/454, $12 \%)$, and episcleritis (44/454, 10\%).

A total of 76 patients were withdrawn from the study (Fig 1). The withdrawal rates were comparable between famciclovir and aciclovir recipients $(46 / 251,18 \%$ and $30 / 203,15 \%$, respectively). No differences were noted between treatment groups in the percentage of withdrawals due to lack of efficacy or adverse events.

The majority of patients ( $\geqslant 95 \%)$ in each treatment group were compliant with study 
Table 4 Ocular manifestations of herpes zoster during the study

\begin{tabular}{llll}
\hline & $\begin{array}{l}\text { Famciclovir 500 mg three } \\
\text { times daily }(n=245)\end{array}$ & $\begin{array}{l}\text { Aciclovir } 800 \mathrm{mg} 5 \times \\
\text { daily }(n=196)\end{array}$ & \\
\cline { 2 - 3 } & No (\%) & No (\%) & Odds ratio $(95 \%$ CI)* \\
\hline Overall & $142(58.0 \%)$ & $114(58.2 \%)$ & $0.99(0.68,1.45)$ \\
Severe & $101(41.2 \%)$ & $78(39.8 \%)$ & $1.06(0.72,1.56)$ \\
Non-severe & $110(44.9 \%)$ & $85(43.4 \%)$ & $1.06(0.73,1.55)$ \\
\hline
\end{tabular}

^Not statistically significantly different if $95 \%$ CI includes 1.0 .

Table 5 Percentage of patients who experienced individual severe ocular manifestations of herpes zoster $(\geqslant 5 \%$ in either group) *

\begin{tabular}{lll}
\hline & \multicolumn{2}{l}{ Treatment group } \\
\cline { 2 - 3 } Severe ocular manifestations & $\begin{array}{l}\text { Famciclovir } 500 \text { mg three } \\
\text { times daily }\end{array}$ & Aciclovir 800 mg $5 \times$ daily \\
\hline Anterior uveitis & $25 \%$ & $25 \%$ \\
Keratic precipitates & $22 \%$ & $22 \%$ \\
Iridocyclitis & $16 \%$ & $16 \%$ \\
Overall keratitis & $13 \%$ & $18 \%$ \\
Glaucoma & $11 \%$ & $14 \%$ \\
Disciform stromal keratitis & $7 \%$ & $12 \%$ \\
Other keratitis & $5 \%$ & $4 \%$ \\
Paralytic ptosis & $5 \%$ & $5 \%$ \\
Stromal keratitis & $5 \%$ & $9 \%$
\end{tabular}

${ }^{\star}$ Each percentage is based on the number of patients in the treatment group minus those patients who had the manifestation in question at baseline and those patients who had no data for the manifestation post-first dose of study medication.

†Includes stromal and disciform stromal types of keratitis.

Table 6 Percentage of patients who experienced individual non-severe ocular manifestations of herpes zoster ( $\geqslant 5 \%$ in either group) *

\begin{tabular}{lll}
\hline & \multicolumn{2}{l}{ Treatment group } \\
\cline { 2 - 3 } Non-severe ocular manifestations & $\begin{array}{l}\text { Famciclovir 500 mg three } \\
\text { times daily }\end{array}$ & Aciclovir $800 \mathrm{mg} 5 \times$ daily \\
\hline Punctate epithelial keratopathy & $26 \%$ & $21 \%$ \\
Inflammation of the conjunctiva & $20 \%$ & $24 \%$ \\
Anterior subepithelial infiltrates & $18 \%$ & $18 \%$ \\
Dendriform keratopathy & $9 \%$ & $10 \%$ \\
Epithelial defect & $8 \%$ & $9 \%$ \\
Episcleritis & $8 \%$ & $10 \%$ \\
\hline
\end{tabular}

* Each percentage is based on the number of patients in the treatment group minus those patients who had the manifestation in question at baseline and those patients who had no data for the manifestation post-first dose of study medication.

medication (that is, received $\geqslant 80 \%$ of study medication).

ANALYSIS

The percentage of patients who experienced an ocular manifestation during the study was similar for famciclovir (142/245, 58.0\%) and aciclovir (114/196, 58.2\%) groups (Table 4). The odds ratio of 0.99 indicated that an ocular manifestation was as likely to occur in either treatment group. There was no significant difference between treatment groups (95\% CI for odds ratio $0.68,1.45)$.

The percentage of patients who experienced severe ocular manifestations during the study was also similar between famciclovir (101/245, $41.2 \%)$ and aciclovir recipients (78/196, $39.8 \%$ ) as was the percentage of patients who experienced non-severe ocular manifestations during the study (famciclovir, 110/245, 44.9\%; aciclovir, 85/196, 43.4\%) (Table 4). There was no significant difference between treatment groups for either of these $(95 \%$ CI for odds ratio $0.72,1.56$ for severe and $0.73,1.55$ for non-severe).

Furthermore, the prevalence of the individual severe and non-severe ocular manifestations was comparable between treatment groups. The most common severe manifestations included anterior uveitis (25\%), keratic precipitates (22\%), overall keratitis (includes stromal and disciform stromal types) (16\%), iridocyclitis (16\%), glaucoma (12\%), and disciform stromal keratitis (9\%) (Table 5). The most common non-severe manifestations were punctate epithelial keratopathy (24\%), inflammation of the conjunctiva $(22 \%)$, and anterior subepithelial infiltrates (18\%) (Table 6).

More than twice as many aciclovir recipients experienced a loss in visual acuity (12/192, $6.3 \%)$ compared with famciclovir recipients $(6 / 233,2.6 \%)$. Although the odds ratio of 0.4 indicated that aciclovir recipients were more likely to experience this event compared with famciclovir recipients, there was no significant difference between groups (95\% CI for odds ratio $0.15,1.08)$.

\section{ADVERSE EXPERIENCES}

Famciclovir was well tolerated with an adverse event profile comparable to aciclovir. The most common on-dose adverse events were nausea $(10 \%)$, headache $(5 \%)$, and vomiting (5\%).

\section{LABORATORY TESTS}

While there were isolated differences in laboratory values between treatment groups no consistent pattern could be identified. In general, the prevalence of laboratory abnormalities was infrequent and comparable between the famciclovir and aciclovir groups.

\section{Discussion}

In view of the potentially serious long term complications of ophthalmic herpes zoster (HZO), appropriate and timely treatment is advocated. Aciclovir treatment has been shown to be beneficial in the treatment of ophthalmic zoster and is currently the standard of care among healthcare practitioners. ${ }^{4-6}$ However, aciclovir has poor and variable bioavailability requiring high frequency dosing regimens which can lead to difficulties with compliance. ${ }^{9}{ }^{10}$ Famciclovir, having greater bioavailability and a longer intracellular half life compared with aciclovir when dosed only three times daily, ${ }^{12}{ }^{13}$ has proved efficacy in the treatment of uncomplicated herpes zoster, both in aciclovir controlled ${ }^{14-16}$ and placebo controlled ${ }^{17}$ trials. This study was therefore set up to compare famciclovir and aciclovir for treatment of HZO.

The percentage of patients with ocular manifestations during the study was the primary efficacy parameter. Although powered to demonstrate superiority of famciclovir over aciclovir in the primary end point, the results demonstrated the two treatments were clinically equivalent (famciclovir, 58.0\%; aciclovir, $58.2 \% ; 95 \%$ CI for difference $-9.47 \%, 9.06 \%$ ) with no significant difference (OR 0.99, 95\% CI for odds ratio $0.68,1.45)$. As with the presence of ocular manifestations during the study, there were no significant differences between the treatments in the development of severe and non-severe ocular manifestations and the percentages were comparable. 
This is the largest controlled study of patients with HZO to date. Direct comparisons with the limited data in the literature are difficult owing to differences in study design, composite end points, and definitions of ocular manifestations. However, the percentage of famciclovir recipients with ocular manifestations in this study is similar to that previously reported for aciclovir treated patients with HZO. Furthermore, the percentage of famciclovir treated patients with ocular manifestations is markedly reduced compared with that reported for untreated patients. ${ }^{781819}$

Anterior uveitis, one of the most common long term complications of $\mathrm{HZO}$ contributing to vision loss, was the most frequently observed severe ocular manifestation in the current study ( $25 \%$ in both groups). This result is similar to the prevalence of anterior uveitis in aciclovir treated patients in the study by Cobo et $a{ }^{7}{ }^{7}$ In that small $(\mathrm{n}=71)$ placebo controlled trial of oral aciclovir (600 mg five times daily for 10 days), anterior uveitis was observed in $19 \%$ of aciclovir recipients compared with $56 \%$ of placebo recipients, and the result was statistically significant $(\mathrm{p}=0.0020)$. The prevalence of anterior uveitis in the current study is also similar to the incidence observed in aciclovir recipients in the study by Harding and Porter. ${ }^{8}$ In that small $(n=46)$ placebo controlled study evaluating oral aciclovir $800 \mathrm{mg}$ five times daily for 10 days, $30 \%$ of aciclovir recipients (seven patients) developed anterior uveitis compared with $53 \%$ of placebo recipients (10 patients; $\mathrm{p}=0.06)$. The percentage of famciclovir treated patients who developed anterior uveitis in the current study was lower than that reported for untreated patients in the natural history study by Harding ( $50 \%$ with complications; anterior uveitis observed in $92 \%){ }^{18}$

The prevalence of keratic precipitates, a clinical indicator of anterior uveitis and the second most frequently observed severe ocular manifestation in the current study $(22 \%$ in both groups) was comparable to that observed in aciclovir recipients (19\%) and much lower than that observed in placebo recipients $(\sim 50 \%)$ in the study by Cobo et $a .^{7}$

Keratitis is another common long term complication of ophthalmic zoster contributing to vision loss. In the current study, the prevalence of overall keratitis (includes stromal, disciform stromal, and keratitis classified as "other") was slightly higher in aciclovir recipients (18\%) compared with famciclovir recipients (13\%). The prevalence of keratitis in the current study was lower than that reported for aciclovir recipients in the literature. In a small study ( $\mathrm{n}$ $=86$ ) by Hoang-Xuan et al, ${ }^{19}$ oral aciclovir 800 $\mathrm{mg}$ five times daily was administered for either 7 or 14 days for treatment of ophthalmic zoster. Topical aciclovir ointment was used concomitantly by all patients. The most common long term complication (appearing or persisting after the first month of the onset of herpes zoster) in aciclovir recipients was stromal keratitis $(27 \%)$. In the study by Cobo et $a l,{ }^{7}$ stromal keratitis was also one of the most common ocular complications, observed in $25 \%$ of aciclovir recipients compared with $56 \%$ of placebo recipients. In the natural history study by Harding, ${ }^{18}$ ocular complications were observed in half of untreated patients and the various varieties of keratitis affected $50 \%$ of these patients.

The prevalence of the non-severe ocular manifestations, dendriform keratopathy $(10 \%)$ and episcleritis (9\%), in the current study was comparable in famciclovir and aciclovir recipients and similar to the prevalence of dendriform keratopathy (14\%) and episcleritis (14\%) in aciclovir recipients in the study by Cobo et $a l,{ }^{7}$ in which the percentages of placebo recipients with dendriform keratopathy and episcleritis were $31 \%$ and $20 \%$, respectively.

Scleritis and iris atrophy were rare in the current study. Fewer than $2 \%$ of patients in each treatment group experienced scleritis. Iris atrophy was observed in $2 \%$ and $4 \%$ of famciclovir and aciclovir recipients, respectively. The percentage of aciclovir recipients with scleritis $(3 \%)$ and iris atrophy (3\%) in the study by Cobo et $a l^{7}$ is similar. However, scleritis and iris atrophy were observed in $15 \%$ and $11 \%$ of placebo recipients, respectively.

In summary, famciclovir $500 \mathrm{mg}$ three times daily demonstrated efficacy similar to aciclovir $800 \mathrm{mg}$ five times daily in the treatment of ophthalmic herpes zoster, but provides patients with a more convenient dosing regimen. There was no statistically significant difference between three times daily famciclovir and five times daily aciclovir for any of the efficacy endpoints and the data from this large study provide evidence that the two treatments are clinically comparable. The percentages of individual ocular manifestations in the current study compare favourably with those reported for aciclovir recipients in the literature and are markedly lower than those reported for untreated patients.

For the Collaborative Famciclovir Ophthalmic Zoster Research Group:

Austria: Peter Fritsch, MD, Innsbruck; Belgium: Laure E Caspers-Velu, MD, University Hospital Saint-Pierre, Brussels; Canada: Fred Y Aoki, MD, Health Sciences Centre Hospital, Winnipeg, Manitoba; ; Marilyn B Ekins, Health Sciences Centre Hospital, Winnipeg, Manitoba; John N Macleod, MD, Oshawa Clinic, Oshawa, Ontario; Pamela H Orr, Health Sciences Centre Hospital, Winnipeg, Manitoba; Kim A Papp,
MD, Probity Medical Research, Waterloo, Ontario; Stephen D Shafran, MD, University of Alberta, Edmonton, Alberta; $\mathrm{H}$ Kenneth R Shutt, Royal Alexandra Hospital, Edmonton, Alberta; Kurt E Williams, MD, Royal University Hospital, Saskatoon, Saskatchewan; Czech Republic: Frantisek Vosmik, MD, Charles' University, Praha; France: Marie-Caroline Pousset, MD, Nantes; Xrsier Papillon, MD, Pornic; Didier Leloup, MD, $\mathrm{MD}$, Nantes; Xavier Papillon, MD, Pornic; Didier Leloup, $\mathrm{MD}$, Reze; Jacques Sicard, MD, St Romain sur Cher; Pascal Voiriot, $\mathrm{PhD}$, Nancy University Hospital, Vandoeuvre-Les-Nancy; Thierry Garaffiny, MD, Geol; Andre Ponsot, MD, Toulon; Francois Spilthooren, MD, Evreux; Germany: Gerd Plewig, MD, Ludwig-Maximilians-University of Munich, Munich; Johannes Ring, MD, PhD, Dermatological Hospital of the Technical University, Munich; Detlef Petzoldt, MD, Dermatologic Hospital of the Ruprecht-Karls-University, Heidelberg; Juergen Knop, MD, PhD, Johannes Gutenberg Universitat, Mainz; Christine Regina Neumann, MD, University of Goettingen, Goettingen; Gerd E Gross, MD, University-Hospital of Hamburg-Eppendorf, Hamburg; H H Wolff, MD, Medical University of Lubeck, Lubeck; Uwe-Frithjof Haustein, MD, University of Leipzig, Leipzig; Ernst G Jung, MD, University of Heidelberg, Mannheim Medical School, Heidelberg; Ireland: Darragh O'Doherty, MD, Wexford; Peter Eustace, FRC Ophth, Institute of Ophthalmology, Dublin; Israel: Shlomo Segev, MD, Sheba Medical Centre, Tel Aviv; Abraham Morag, MD, Hadassah Hospital, Jerusalem; Raul Raz MD, Haemek Hospital, sah Hospital, Jerusalem, Raul Raz, MD, Haemek Hospital, Afula; Italy: Pietro Carlo Biggio, MD, University of Cagliari, Cagliari; Giampaolo Vezzoni, MD, Massa-Carrara Hospital, Massa-Carrara; Lucio Andreassi, MD, University of Sienna, Sienna; Giuseppe Galbiati, MD, S Gerardo di Monza Hospital, Monza; Annarosa Virgili, MD, S Anna Hospital, Ferrara
University; Monica Corraza; MD, S Anna Hospital, Ferrara 
University; Oreste Primiceri, MD, Civic Hospital Vito Fazzi, Llovak Republic: Jozef Buchvald, MD, Comenius University, Slovak Republic: Jozef Buchvald, MD, Comenius University, Bratislava; Spain: Mariano Casado Jimenez, MD, PhD, Hospital La Paz, Madrid; Eduardo Escario Travesedo, MD, PhD, General Hospital of Albacete, Albacete; Jesus M Borbujo Martinez, MD, PhD, General Hospital of Mostoles, Madrid; Switzerland: Edoardo Baglivo, MD, Hospital Cantonal Universitaire Geneve, Geneve; United Kingdom: Timothy J Leonard, FRCS, Charing Cross Hospital, London; Andrew J Morrell, FRC Ophth, St James's University Hospital, Leeds; Baljean Dhillon, FRC Ophth, Princess Alexandra Eye Pavillion, Edinburgh; Stuart Roxburgh, FRC Ophth, Ninewells Hospital, Dundee; Anthony J Bron, FRC Ophth, Nuffield Lab of Ophthalmology, Oxford; David V Ingram, FRC Ophth, Sussex Eye Hospital, Brighton; United States: John D Sheppard, MD, Virginia Eye Consultants, Norfolk, VA; Margaret A Drehobl, MD, Centre for Health Care, San Diego, CA; Jay S Pepose, $\mathrm{MD}$, PhD, Washington University School of Medicine, St Louis, MO; Patrick M Flaharty, MD, Eye Centers of Florida, Ft Louis, MO; Patrick M Flaharty, MD, Eye Centers of Florida, Ft Myers, FL; Walter Atlas, MD, Nalle Clinic, Charlotte, NC;
Herbert E Kaufman, MD, LSU Eye Center, New Orleans, LA; Herbert E Kaufman, MD, LSU Eye Center, New Orleans, LA;
Paul E Cutarelli, MD, University Hospitals of Cleveland and Paul E Cutarelli, MD, University Hospitals of Cleveland and Case Western Reserve University, Cleveland, OH; J Terrence Coyle, MD, Eye Clinic of Bellevue, Ltd, PS Snoqualmie Valley Clinic, Bellevue, WA; Peter G Jones, MD, Rainier Clinical
Research Center, Inc, Renton, WA; Joseph Tauber, MD, St Luke's Hospital of Kansas City, Kansas City, MO; Penny A Asbell, MD, The Mount Sinai Medical Center, New York, NY Richard F Beatty, MD, University of Colorado Health Sciences Center, Denver, CO; Peter R Laibson, MD, Wills Eye Hospital, Philadelphia, PA; James T Rosenbaum, MD, Oregon Health Sciences University, Portland, OR; Adelaide A Hebert, MD University of Texas Health Science Center, Houston, TX. Amit G Pandya, MD, University of Texas Southwestern Medical Center, Dallas, TX; G Richard Cohen, MD, Boca Ratodical Eric D Donn TX Eric D Dallege, New $\mathrm{MD}$, Scripps Clnic, La Jolla, CA; John F Stamler, MD, PhD, Eye Physicians and Surgeons, Iowa City, IA; John D Kriesel, MD, University of Utah, Salt Lake City, UT; David G Heic.

The authors wish to acknowledge the contribution of the following individuals to the conduct and analysis of this study: Christiane Marechal, MD, Center Hospital of Sart Tilman, Sart Tilman; Michel Lassonde, MD, Hospital of Notre Dame, Montreal, Quebec; Alain Y Martel, MD, Centre Hôp de l'Université Laval, Ste-Foy, Quebec; Alain El Sawy, MD, St Martin D'heres; Guy Omnes, MD, Plouguerneau; Aidan Murray, FRCS, Cork University Hospital, Cork; Ruth Lang, MD, Meir Hospital, Kfar-Saba; Carmelo Scarpa, MD, Dell' Universita di Trieste, Trieste; Carl P Herbort, MD, La Source Eye Center, Lausanne; David L Easty, DO, Bristol Eye Hospital, Bristol; Alan S Mushin, MD, The Royal London Hospital, London; Howard Mushin, Rosenblum WN, Rich, Malley Clinic, Wenatchee, WA; Susan Law

This study was funded by SmithKline Beecham PharmaceuThis study was funded by SmithKline Beecha

icals, Collegeville, PA, USA, and Harlow, UK.

Presented in part at the 38th Interscience Conference on Antimicrobial Agents and Chemotherapy, San Diego, California, USA, September 1998 (Abstract LB-3) and the American Academy of Ophthalmology/Pan-American Association of Ophthalmology Joint Meeting, Orlando, Florida, USA, October 1999 (Abstract 254).
1 Womack, LW, Liesegang, TJ. Complications of herpes zoster ophthalmicus. Arch Ophthalmol 1983;101:42-5.

2 Cobo M, Foulks GN, Liesegang T, et al. Observations on the natural history of herpes zoster ophthalmicus. Curr Eye Res 1987;6:196-9.

3 Harding SP, Lipton JR, Wells JCD. Natural history of herpes zoster ophthalmicus: predictors of postherpetic neuralgia and ocular involvement. Br Ophthalmol 1987;71:353-8.

4 Huff, JC. Oral acyclovir therapy of acute herpes zoster: a multi-centre study. Research and Clinical Forms 1987;9:3743.

5 Morton P, Thomas A. Oral acyclovir in the treatment of herpes zoster in general practice. NZ Med f 1989;102:93-5.

6 McKendrick MW, McGill JI, White JE, et al. Oral acyclovir in acute herpes zoster. BMF 1986;293:1529-32.

7 Cobo LM, Foulks GN, Liesegang T, et al. Oral acyclovir in the treatment of acute herpes zoster ophthalmicus. Ophthalmology 1986;93:763-70.

8 Harding SP, Porter SM. Oral acyclovir in herpes zoster ophthalmicus. Curr Eye Res 1991;10:177-82.

9 O'Brien JJ, Camoli-Richards DM. Acyclovir: an updated review of it antiviral activity, pharmacokinetic properties and therapeutic efficacy. Drugs 1989;37:233-309.

10 Wade JC, Newton RM, Flournoy N, et al. Oral acyclovir for prevention of herpes simplex virus reactivation after marrow transplantation. Ann Intern Med 1984;100:823-8.

11 Pue MA, Pratt SK, Fairless AF, et al. Linear pharmacokinetics of penciclovir following administration of single oral doses of famciclovir $125,250,500$ and $750 \mathrm{mg}$. $\mathcal{F}$ Antimicrob Chemother 1994;33:119-27.

12 DeMiranda P, Blum MR. Pharmacokinetics of acyclovir after intravenous and oral administration. I Antimicrob Chemother 1983;12(suppl B):29-37.

13 Boyd MR. Update on famciclovir. In: Mills J, Corey L, eds. Antiviral chemotherapy: new directions for clinical application and research. Englewood Cliffs, NJ: Prentice Hall International, 1989;9:83-96.

14 Candaele M, Candaele D, on behalf of the Famciclovir Herpes Zoster Clinical Study Group. Famciclovir: confirmed efficacy of $250 \mathrm{mg}$ tid for the treatment of herpes zoster infection. Seventh International Conference on Antiviral Research (Abstract 118), Charleston, South Carolina, 27 February-4 March 1994

15 Degreef H, Famciclovir Herpes Zoster Clinical Study Group. Famciclovir, a new oral antiherpes drug: results of the first controlled clinical study demonstrating its efficacy and safety in the treatment of uncomplicated herpes zoster in immunocompetent patients. Int $\mathcal{F}$ Antimicrob Agents 1994;4:241-6.

16 Portnoy J, on behalf of the Famciclovir Herpes Zoster Clinical Study Group. Famciclovir in the treatment of herpes zoster infection. Seventh International Conference on Antiviral Research (Abstract 119), Charleston, South Carolina, 27 February-4 March 1994

17 Tyring S, Barbarash RA, Nahlik JE, et al. Famciclovir for the treatment of acute herpes zoster. Effects on acute disease and postherpetic neuralgia: a randomized, double-blind, alacebo-controlled trial. Ann Intern Med 1995;123:89-96.

18 Harding SP. Management of ophthalmic zoster. 7 Med Virol 1993;(Suppl 1):97-101.

19 Hoang-Xuan T, Buchi ER, Herbort CP, et al. Oral acyclovir for herpes zoster ophthalmicus. Ophthalmology 1992;99: $1062-70$. 